EGU2020-4949

https://doi.org/10.5194/egusphere-egu2020-4949

EGU General Assembly 2020

(c) Author(s) 2021. This work is distributed under

the Creative Commons Attribution 4.0 License.

\title{
Optimizing the potential of iron oxide-based tracers
}

\author{
Gema Guzmán ${ }^{1}$, Azahara Ramos ${ }^{1}$, Vidal Barrón², and José A. Gómez ${ }^{1}$ \\ ${ }^{1}$ Institute for Sustainable Agriculture-CSIC, Spain (gemaguzmandiaz@ias.csic.es; aramos@ias.csic.es; \\ joseagomez@ias.csic.es) \\ ²University of Cordoba, Spain (vidal@uco.es)
}

So far, it does not exist a set of tracers which fulfill all the characteristics for being an ideal sediment tracer such as, environmentally friendly, inexpensive or easily analysed (Zhang et al., 2001). For this reason, and in order to address some of the unsolved issues of water erosion processes, more research enquiring into the development of these soil and sediment tracers is needed.

Iron oxide-based tracers has been already tested in several water erosion trials with satisfactory results (e.g. Guzmán et al., 2010, 2013, 2015). In 2015, three cascade plots with a different iron oxide (magnetite, hematite and goethite) each were set up in order to evaluate soil redistribution after the rainy season (Obereder et al., 2016). While these authors presented the total iron content of sediments after clorhydric acid extraction, the present study will show only the free iron content of soil and sediments using a different extraction method (CBC, citrate-bicarbonate-ditionite), as this method is more adequate in high iron content soils, as is our case.

The results depict the suitability of the CBD method extracting the three tracers with an average recovery rate of 0.7 . The analysis of the iron content of soil and sediment samples indicates a relatively low movement of soil although showing significant statistical differences with background and mixture values. These results are in line with the ones detected by the magnetic susceptibility measurements. Further textural and visible spectrum analysis of the samples will allow to determine the possible selectivity factor and to discriminate qualitative and quantitatively hematite and goethite tracers, respectively.

References:

Guzmán et al. 2010. Catena, 82(2), 126-133.

Guzmán et al. 2013. Soil Science Society of America Journal, 77(2), 350-361.

Guzmán et al. 2015. Journal of hydrology, 524, 227-242.

Obereder et al. 2016. Geophysical Research Abstracts Vol. 18, EGU2016-2455-1. EGU General Assembly 2016.

Zhang et al. 2001. Soil Science Society of America Journal, 65(5), 1508-1515. 
